\title{
Experimental Research of Aggregate Strength on the Compressive Strength of Recycled Concrete
}

\author{
LIANG Yuehua ${ }^{1,2}$, WANG Jie Ji,2, WU Feng $^{1,2}$ \\ ${ }^{1}$ School of Civil Engineering and Architecture, Panzhihua University, \\ Panzhihua 617000, Sichuan, China \\ 2 Vanadium and Titanium Resource Compressive Utilization Key Laboratory of Sichuan Province, \\ Panzhihua 617000, Sichuan, China
}

Keywords: Waste; recycled coarse aggregate; Design strength; recycled concrete; Compressive performance.

Abstract: The current recycled concrete is mainly poured by directly taking construction waste after being crushed by classification, cleaned, and gradated as fine and coarse aggregate. The waste is not used according to the classifications of different strength, but is mixed and used uniformly. The impact of recycled aggregate's strength on the strength of recycled concrete is not considered. Aiming at the reinforced concrete of the high-titanium and the blast furnace slag, the effects of construction waste with different strength on recycled concrete of high-titanium slag are studied. By changing the strength of recycled coarse aggregate and design strength, the effects on the compressive performance of recycled concrete are studied. The experiment proves that when the replacement rate is $100 \%$ and the design strength is constant, increasing the strength of recycled coarse aggregate properly helps to enhance the strength of recycled concrete. The prepared recycled concrete can be used in road engineering.

\section{Introduction}

High-titanium and blast furnace slag is a kind of porous blast furnace slag produced during the process of melting vanadium-titanium in Panzhihua Iron and Steel Company. In recent years, through a series of experiments and theoretical researches, high-titanium and blast furnace slag has been largely used as the fine and coarse aggregate in concrete engineering, and the strength has obvious advantages over ordinary concrete[1].

Under the background of vigorously advocating the "energy conservation and emissions reduction" in China, the reuse of waste concrete is increasingly gaining widespread attention. recycled concrete technology is that after being crushed, cleaned, processed, and gradated, waste concrete is mixed and becomes recycled aggregate according to a certain proportion, and then partly or wholly substitutes the natural aggregate to prepare new concrete. Waste concrete is recycled. It is a good solution to well solve the transporting, stacking and handling problems of waste building materials, and the effective recycling of waste concrete can also be achieved. recycled concrete technology is significant for the sustainable development of the construction industry and the construction of a conservation-oriented society with huge economic and social benefits, and is considered to be one of the main measures to develop green ecological concrete.

As early as post-World War II, some developed countries in the world have carried out studies on recycled concrete, and some important research achievements have been obtained. These researches are still ongoing and developing. In recent years, some domestic experts and scholars have also conducted some extensive studies in this field [2,3], but the researches still needs to be done in depth.

In this paper, the compressive strength of fully recycled concrete with different recycled aggregate strength and different ratios is studied.

\section{Experimental Design and Implementation}

Experimental Plan Design. To study the effect of recycled aggregate's strength on the compressive strength of fully recycled concrete, concrete waste with different strength (ie, 36.0Mpa, 41.0Mpa, 
$52.0 \mathrm{Mpa}, 57.0 \mathrm{Mpa}$ ) is taken to respectively pour fully recycled standard concrete specimens with design strength of C30, C35 and C40 and then compressive strength experiment is made on specimens. The plan design is shown in Table 2.1.

Table 2.1 Experimental plan design

\begin{tabular}{cccc}
\hline $\begin{array}{c}\text { Grad } \\
\mathrm{e}\end{array}$ & $\begin{array}{c}\text { Waste } \\
\text { strength }\end{array}$ & $\begin{array}{c}\text { Group } \\
\text { number/p } \\
\text { iece }\end{array}$ & $\begin{array}{c}\text { Specimen } \\
\text { s size }\end{array}$ \\
\hline & $36 \mathrm{Mpa}$ & $1(3)$ & $\begin{array}{c}150^{*} 150^{*} \\
150\end{array}$ \\
\cline { 2 - 4 } $\mathrm{C} 30$ & $42 \mathrm{Mpa}$ & $1(3)$ & $\begin{array}{c}150^{*} 150^{*} \\
150\end{array}$ \\
$\mathrm{C} 35$ & $52 \mathrm{Mpa}$ & $1(3)$ & $\begin{array}{c}150^{*} 150^{*} \\
150\end{array}$ \\
$\mathrm{nyyy} \mathrm{C} 40$ & $57 \mathrm{Mpa}$ & $1(3)$ & $\begin{array}{c}150^{*} 150^{*} \\
150\end{array}$ \\
\cline { 2 - 4 } & &
\end{tabular}

Mixture Ratio Design of Experimental Materials. The mixture ratio design of fully recycled concrete is based on that of ordinary concrete of high-titanium and blast furnace slag, as shown in Table 2.2.

Table 2.2 Experimental mixture ratio design

\begin{tabular}{|c|c|c|c|c|c|c|c|c|}
\hline \multirow{3}{*}{$\begin{array}{l}\text { Stren } \\
\text { gth } \\
\text { desig } \\
\text { n }\end{array}$} & \multirow[b]{2}{*}{$\begin{array}{c}\text { Water-bi } \\
\text { nder } \\
\text { ratio }\end{array}$} & \multirow[b]{2}{*}{ 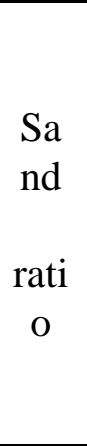 } & \multicolumn{6}{|c|}{$\begin{array}{l}\text { Actual amount of each material in } \\
\text { concrete }[\mathrm{kg} / \mathrm{m} 3]\end{array}$} \\
\hline & & & $\begin{array}{c}32.5 \\
\text { Cem } \\
\text { ent }\end{array}$ & $\begin{array}{c}42.5 \\
\text { Cem } \\
\text { ent }\end{array}$ & $\begin{array}{c}\text { Blas } \\
t \\
\text { furn } \\
\text { ace } \\
\text { slag } \\
\text { sand }\end{array}$ & $\begin{array}{l}\text { Recyc } \\
\text { led } \\
\text { coarse } \\
\text { aggre } \\
\text { gate }\end{array}$ & $\begin{array}{l}\text { Fly } \\
\text { ash }\end{array}$ & $\begin{array}{l}\text { wat } \\
\text { er }\end{array}$ \\
\hline & $\%$ & $\%$ & $\mathrm{Kg}$ & $\mathrm{Kg}$ & $\mathrm{Kg}$ & $\mathrm{Kg}$ & $\mathrm{Kg}$ & $\mathrm{Kg}$ \\
\hline C30 & 42 & 50 & 303 & 0 & 932 & 932 & $\begin{array}{l}92 . \\
95\end{array}$ & 268 \\
\hline C35 & 40 & 49 & 0 & 298 & 881 & 958 & $\begin{array}{l}91 . \\
83\end{array}$ & 258 \\
\hline $\mathrm{C} 40$ & 38 & 48 & 0 & 332 & 823 & 954 & $\begin{array}{l}99 . \\
07\end{array}$ & 262 \\
\hline
\end{tabular}

Making, Curing and Testing Specimens. According to the experimental design plan in Table 2.2 and experimental mixture ratio in Table 2.3, fully recycled standard concrete specimens are poured respectively. Under standard conditions, concrete specimens are cured for 28 days[4], and then according to the standard, standard compression experiment with concrete is done[5], recording the actual size and compressive strength of concrete specimens.

\section{Experimental Results Analysis}

The experimental results indicate that with the increase of the strength of recycled coarse aggregate, compressive strength of fully recycled concrete shows a tendency to increase first and then decrease. Under certain recycled coarse aggregate strength, the improvement of design strength makes the compressive strength of the fully recycled concrete gradually increase.

Effects of Coarse Aggregate's Strength on Compressive Strength of Recycled Concrete. When the design strength is C30, C35 and C40, the compressive strengths of the fully recycled concrete prepared with different coarse aggregate strengths are shown in Fig 1. 


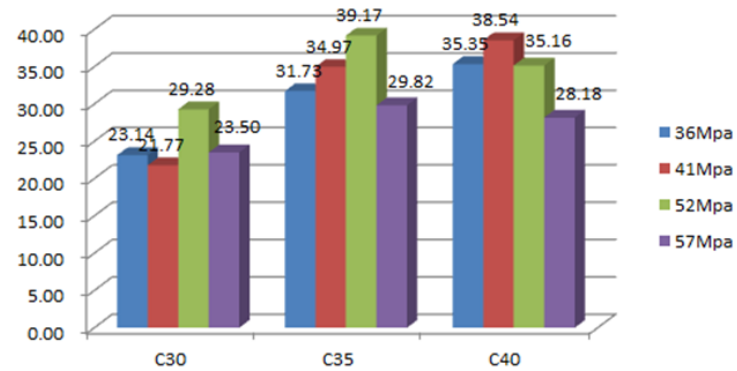

Fig.1 Standard values histogram of fully recycled concrete strengths with different recycled aggregate strengths

Experimental statistics show that on the whole the strength of the fully recycled concrete increases with the increase of aggregate strength first, and then decreases. The linear relation can not be formed.

When the design strength is C30 and the strength of recycled aggregate source is $36 \mathrm{Mpa}, 41 \mathrm{Mpa}$, $52 \mathrm{Mpa}$ and 57Mpa respectively, the standard values of the strength of fully recycled concrete cubes are $23.14 \mathrm{MPa}, 21.77 \mathrm{MPa}, 29.28 \mathrm{MPa}$ and $23.50 \mathrm{MPa}$ respectively, all of which are nearly $20 \%$ lower than the design strength and do not meet the design requirements.

When the design strength is C35 and the strength of recycled aggregate source is $36 \mathrm{Mpa}, 41 \mathrm{Mpa}$, $52 \mathrm{Mpa}$ and 57Mpa respectively, the standard values of the strength of fully recycled concrete cubes are $31.73 \mathrm{MPa}, 34.97 \mathrm{MPa}, 39.17 \mathrm{MPa}$ and $29.82 \mathrm{MPa}$ respectively. The test the strength of recycled aggregate source is $41 \mathrm{MPa}$ basically satisfies the design strength requirements. The test that the strength of recycled aggregate source is $52 \mathrm{MPa}$ meets the design strength requirements; The other two groups can not meet the design strength requirements.

When the design strength is C40 and the strength of recycled aggregate source is $36 \mathrm{Mpa}, 41 \mathrm{Mpa}$, $52 \mathrm{Mpa}$ and 57Mpa respectively, the standard values of the strength of fully recycled concrete cubes is $35.35 \mathrm{MPa}, 38.54 \mathrm{MPa}, 35.16 \mathrm{MPa}$ and $28.18 \mathrm{MPa}$ respectively, which are nearly $15 \%$ lower than design strengths on average. All tests do not meet the design requirements.

Effects of Design Strength on Compressive Strength of Recycled Concrete. When the strength of recycled aggregate source with waste is $36 \mathrm{Mpa}, 41 \mathrm{Mpa}, 52 \mathrm{Mpa}$ and $57 \mathrm{Mpa}$ respectively, the strength of fully recycled concrete with design strength of C30, C35 and C40 is shown in Fig. 2.

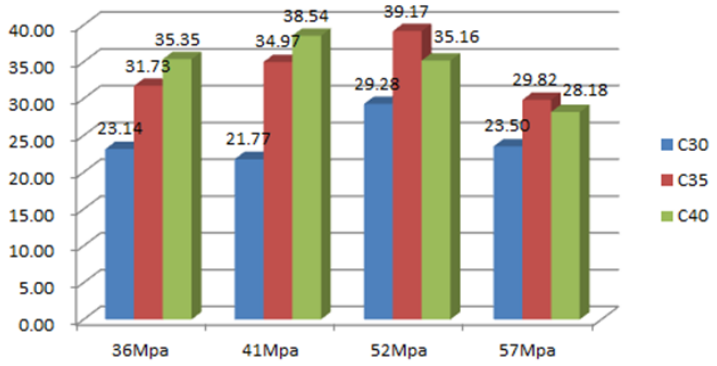

Fig.2 design strengths

When the strength of recycled aggregate source is $36 \mathrm{Mpa}$ and $41 \mathrm{Mpa}$, the experimental results by comparing and analyzing the data show that: Like the ordinary concrete, the compressive strength of the recycled concrete of high-titanium and blast furnace slag increase on the whole with the increase of aggregate strength, but linear relation can not be formed. Compared with the ordinary concrete, the compressive strength of all the recycled concrete prepared according to mixture ratio of ordinary concrete reduce significantly.

Analysis of compressive test on recycled concrete with coarse aggregate strength of $52 \mathrm{Mpa}$ and replacement percentage of $100 \%$ shows that: With the increase of the replacement strength, the compressive strength of recycled concrete of high-titanium and blast furnace slag presents the tendency of rising first and then decreasing, rather than a simple linear relation; And standard values of compressive strength of cubes with design strengths of C30 and C40 are less than cubes' design values, which does not meet the design requirements. Only when the design strength is $\mathrm{C} 35$, the 
standard value of the compressive strength is greater than the design value, which meet the design requirements.

Analysis of compressive test on recycled concrete with coarse aggregate strength of 57Mpa and replacement percentage of $100 \%$ shows that: With the increase of the replacement strength, the compressive strength of recycled concrete of high-titanium and blast furnace slag presents the tendency of rising first and then decreasing, rather than a simple linear relation; And when the design strengths is $\mathrm{C} 30, \mathrm{C} 35$, and C40, all the standard values of compressive strength are less than cubes' design values, which do not meet the design requirements.

Analysis of the reasons for the above phenomenon:

The binding property of the interface between the recycled coarse aggregate for concrete and the cement paste is poor, as the hydration product fails to fill the space of the two, and the structure is relatively loose. However, the binding property of interface between part of recycled coarse aggregate for concrete and cement paste is good, making the recycled aggregate and cement mortar combine closely, and the interface almost can not be seen obviously[6].

The rough surface of the recycled coarse aggregate makes it easy to form a larger physical binding strength with the cement paste; The recycled coarse aggregate has a higher surface activity and is easy to react with the cement slurry to form a higher chemical binding strength, which makes the strength of part of the recycled concrete close to the concrete strength. While the recycled fine aggregate is almost no longer active, and the impurities in the recycled fine aggregate with lower strength will adversely affect the caking property of the interface, resulting in a lower strength of the fully recycled concrete than the strength of corresponding ordinary concrete, which is lower than the strength of partial recycled concrete.

\section{Conclusion}

On the basis of testing on recycled concrete cubes for grades C30、C35、C40 with replacement percentage of $100 \%$ and different recycled coarse aggregate strength (36 Mpa, $41 \mathrm{Mpa}, 52 \mathrm{Mpa}$, $57 \mathrm{Mpa}$ ), contrastive analysis between experimental compressive strength and the theoretical values shows that:

1. When the design strength is the same, the compressive strength of the recycled concrete increases with the initial strength of the coarse aggregate first and then decreases.

2. When the replacement strength is the same, the compressive strength of recycled concrete increases with the increase of initial strength of coarse aggregate.

3. When the design strength is $35 \mathrm{Mpa}$ and the replacement strength of coarse aggregate is $52 \mathrm{Mpa}$, the compressive strength of recycled concrete has certain enhancement.

4. When the replacement percentage of coarse aggregate with different strength is $100 \%$, the coefficient of variation of compressive strength of recycled concrete is not very different, which indicates that the strength of coarse aggregate has little effect on the coefficient of variation of compressive strength of recycled concrete.

5. The standard deviations of the strength of recycled concrete replaced by coarse aggregate with different strength have certain differences.

6. When the replacement rate of coarse aggregate is $100 \%$ and the design strength is $35 \mathrm{Mpa}$, coarse aggregate with high strength can meet the design requirements.

7. In practical engineering, all the waste concrete should not be used by being mixed together, which will seriously affect the compressive strength of recycled concrete. Waste concrete should be used in accordance with the classification.

8. In the absence of joining in steel bar to explore the compressive strength, the current findings are limited to being used in road engineering. 


\section{Acknowledgements}

Project funded by Vanadium and Titanium Resource Compressive Utilization Key Laboratory of Sichuan Province.

\section{References}

[1] H. Huanghua, C. Wei, S. Jingkun, and C. Jiayun, "Application of high-titanium and blast furnace slag in concrete materials", New Building Materials,no.11,pp.71-73,2006 (Chinese).

[2] L. Rong, F. Guangle, and L. Tianqing, "Research review of recycle cement concrete", Journal of Foreign Highway, vol. 23, no. 2, pp. 56-57, 2003 (Chinese).

[3] C. Zongping, X. Jinjun, Z. Huahai, S. Yisheng, X. Jianyang, and L. Juntao, "Basic mechanical properties test and street-strain constitutive relations of recycled coarse aggregate concrete", Journal of Building Materials, vol. 16, no.1, pp. 24-25, 2013 (Chinese).

[4] Standards China, "Standard for test method of mechanical properties on ordinary concrete", GB/T 50081-2002, China Architecture \& Building Press, Beijing, China,pp.10-11,2003 (Chinese).

[5] hod of mechanical properties on ordinary concrete", GB/T 50081-2002, China Architecture \& Building Press, Beijing,China,pp.12-15, 2003 (Chinese). 